\title{
Phyllode inoculation provides a rapid protocol for preliminary screening of Acacia species for tolerance to Ceratocystis wilt and canker disease
}

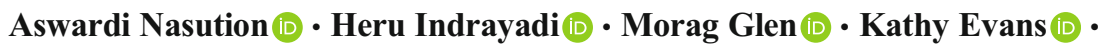 \\ David Ratkowsky (D) - Jeremy Brawner (ID) Abdul Gafur $(\mathbb{D} \cdot$ Caroline Mohammed 1
}

Accepted: 6 February 2022 / Published online: 25 February 2022

(C) The Author(s) 2022

\begin{abstract}
Ceratocystis wilt and canker disease has devastated Acacia mangium plantations in south-east Asia. Current screening methodologies to identify resistant or tolerant germplasm use potted plants in a greenhouse as a preliminary screening to select material for field trials, but these tests are time-consuming, motivating a search for rapid screening protocols. In this study, inoculation procedures were tested on three species of Acacia, viz. A. mangium, A. crassicarpa and a hybrid of A. auriculiformis and A. mangium, using three isolates of Ceratocystis manginecans. Mycelial plugs were compared with spore suspensions as inoculum to infect artificial wounds on the stems of $A$. mangium potted plants. The rapid screening protocols involved
\end{abstract}

A. Nasution
PT Riau Andalan Pulp and Paper, Pangkalan Kerinci Timur,
Pangkalan Kerinci, Pelalawan Regency, Riau 28654, Indonesia

H. Indrayadi · A. Gafur

PT Arara Abadi - Sinarmas Forestry Research and Development, Siak Regency, Riau 28685, Indonesia

H. Indrayadi $\cdot$ M. Glen $(\bowtie) \cdot$ K. Evans $\cdot$

. Ratkowsky $\cdot$ C. Mohammed

Tasmanian Institute of Agriculture, University of Tasmania,

Private Bag 98, Hobart, Tasmania 7001, Australia

e-mail: Morag.Glen@utas.edu.au

J. Brawner

Department of Plant Pathology, University of Florida, 1401 Fifield Hall, 2570 Hull Road, Gainesville, FL 32611, USA inoculation of stem segments with mycelial plugs and detached phyllodes with a spore suspension, with susceptibility measured by lesion length on the stems or necrosis length on the phyllodes. Both mycelial plugs and spore suspensions produced a similar level of disease incidence, so either inoculum form can be used for an assay. The stem segments were prone to contamination by other fungi and to desiccation, while results from the potted plant and phyllode protocols showed similar trends of susceptibility among the Acacia clones and species. The ease, rapidity, and reproducibility of the phyllode inoculation protocol makes it a potential replacement for inoculation of potted plants as a preliminary screening protocol to identify disease tolerant A. mangium germplasm prior to field screening.

Keywords Acacia mangium - Acacia crassicarpa . Acacia auriculiformis · Ceratocystis manginecans . Ceratocystis fimbriata

\section{Introduction}

With accelerating pest impacts on forest productivity (Jactel et al., 2020), the incorporation of selection for tolerance or resistance to pests and/or diseases is receiving increasing recognition as a vital component of tree breeding programs (Woodcock et al., 2019). This is acknowledged as a long-term objective, with the final selection based on replicated field trials (Brawner et al., 
2015), though methods to expedite the process and to increase the potential value from field trials by conducting preliminary screening have been explored (Pais et al., 2018; Devkota \& Hammerschmidt, 2019; Beier \& Blanchette, 2020). In this paper we describe a rapid method of preliminary screening to select acacias with tolerance to wilt and canker disease caused by Ceratocystis manginecans.

In Southeast Asia, species of Eucalyptus L'Hér. and Acacia Mill. have been planted in 25.6 million hectares of forest plantations, mainly in China, India, Indonesia, Malaysia, Thailand and Vietnam (Harwood \& Nambiar, 2014b). These fast-growing exotic hardwoods were established to meet the demand of raw materials for pulp and paper production which, on a global scale, rose substantially from 280 to 500 million tons per annum from 1980 to 2008 (Asia-Pacific Forestry Commission, 2010). The global market for printing and writing papers has been impacted by a consistent decline in production in developed regions such as North America and Europe; however, this has been offset by the increase in the supply of writing paper in other markets, especially the Asia Pacific (Wright, 2014).

Despite promising yields in early rotations (Harwood \& Nambiar, 2014a), disease problems which seriously impact wood productivity are emerging in these exotic hardwood plantations, especially in A. mangium Willd. (Nambiar \& Harwood, 2014). A root rot caused by the native pathogen Ganoderma philippii (Bres. \& Henn. ex Sacc.) Bres. can significantly reduce A. mangium productivity, especially as the number of rotations increase (Francis et al., 2014; Mohammed et al., 2014). A vascular wilt and canker disease caused by a Ceratocystis sp. in Indonesia, Vietnam and Malaysia is of particular concern and is causing large scale mortalities of A. mangium (Tarigan et al., 2011a; Thu et al., 2012; Brawner et al., 2015). With productivity greatly reduced due to G. philippii and a Ceratocystis sp., there is a shift to planting Eucalyptus species rather than A. mangium (Nambiar \& Harwood, 2014).

The species that causes canker and wilt disease of A. mangium in Indonesia was described as a new species, Ceratocystis acaciivora Tarigan \& M. van Wyk (Tarigan et al., 2011a), but was subsequently reduced to synonymy with $C$. manginecans M. van Wyk, AlAdawi \& M.J. Wingf. (Fourie et al., 2015). Some authors also consider $C$. manginecans to be a synonym of C. fimbriata Ellis \& Halst. (Oliveira et al., 2015). A recent genome comparison revealed that $C$. fimbriata had $99.3 \%$ nucleotide identity with $C$. manginecans compared to $99.7-99.9 \%$ identity among three isolates of C. manginecans (Fourie et al., 2020). Ceratocystis species differ from true vascular wilts in that they also invade bark and cambium, causing cankers. Bretziella fagacearum (syn. C. fagacearum) is the only member of Ceratocystidaceae that fits the classical definition of a vascular wilt.

Ceratocystis pathogens of trees are commonly spread via spore transmission from infected trees to healthy trees and wounds created by animals, humans or insects can become their entry points (Kile, 1993; Harrington, 2013). Spores are often dispersed by wood- and barkinhabiting beetles which are attracted to the exudations from infected trees (Heath et al., 2009). Frass, ejected from beetle tunnels, may also carry spores and be transported on air currents to infect wounds (Harrington, 2007). A key strategy to prevent transmission of Ceratocystis species among trees is to avoid wounding (Kile, 1993), or to minimize the size of the pruning wound by careful pruning or by conducting pruning operations during the seasons when insect vectors are less active (Heath et al., 2009; Tarigan et al., 2011b). When wounding cannot be avoided, a wound dressing is highly recommended for preventing infection of trees by Ceratocystis species (Harrington, 2013). These types of management strategies are costly and ineffective for large scale A. mangium plantations, especially as the trees require singling because they tend to have multiple stems (Tarigan et al., 2011b), and because they are prone to monkey, squirrel, elephant and wind damage (Hardie et al., 2018).

Genetic resistance by selective breeding of disease tolerant or resistant materials is considered to be the most cost-effective method for controlling disease caused by Ceratocystis species in tropical Acacia plantations (Roux \& Wingfield, 2009). It is useful to distinguish between resistance, i.e. having attributes that prevent trees being infected by a disease, and tolerance, which is the ability of the tree, once infected, to continue to grow and survive (Brawner et al., 2015). Selective breeding to reduce damage from $C$. manginecans will potentially involve genetic improvement in several independent resistance and tolerance traits. Levels of tolerance to disease caused by Ceratocystis species in A. mangium are low and resistance is rarely observed, so large numbers of plants must be screened to obtain a few resistant or tolerant plants for breeding programs (Brawner et al., 2015). Other species such as 
A. auriculiformis Benth. show a greater tolerance to $C$. manginecans (Trang et al., 2017) and hybridisation may offer some hope of transferring tolerance to A. mangium.

The current procedure for the preliminary screening of Acacia trees against disease caused by Ceratocystis species is by inoculation of seedlings or clonal cuttings in the greenhouse. However, this process tends to be slow due to the very large number of plants which must be screened, and the length of time plants must be maintained before disease levels can be assessed. Therefore, a more rapid screening process has the potential to expedite breeding programs (Wingfield et al., 2001).

Few reports are available about rapid procedures to evaluate resistant or tolerant plants against disease caused by Ceratocystis species. In one study, Van Wyk et al. (2010) compared methods which included in vitro growth comparisons on artificial media, inoculations on eucalypt seedlings in a greenhouse, inoculations on eucalypt bolts freshly cut from stems of young trees, and field inoculations on young trees to predict the pathogenicity of a member of the $C$. fimbriata species complex to Eucalyptus spp. Results showed that inoculating eucalypt bolts gave similar results to field inoculations, with the potential benefit that inoculations can be undertaken under quarantine conditions, require less space and would be preferable to inoculations on seedlings. A further study by Magalhães et al. (2016) reported that data obtained from inoculating cacao leaf discs with a closely related species, Ceratocystis cacaofunesta Engelbr. \& T.C. Harr., reflected the field resistance of cacao trees against ceratocystis wilt disease caused by this fungal pathogen and could potentially be used for resistance screening in breeding programs of other plant species. In place of leaves, many acacia species have phyllodes; flattened and widened petioles or leaf stems with distinct veins that run parallel to the longitudinal axis.

The aim of the present study was to improve screening procedures in acacia for susceptibility to wilt and canker disease caused by $C$. manginecans by comparing the current screening protocol (inoculation of whole potted plants) with two potential rapid screening procedures, one using segments of the stems of potted plants and the other involving the inoculation of Acacia phyllodes. We also evaluated whether the expression of tolerance in potted plants is influenced by the type of inoculum (mycelium versus spore suspension).

\section{Materials and methods}

Plant material

The present study consisted of three separate experiments. The first experiment used five clones of A. mangium (AM00021, AM00316, AM00868, AM00870 and AM00887) currently planted on mineral soils in Riau Province, Sumatra, by Riau Andalan Pulp $\&$ Paper (RAPP). The second experiment used six Acacia clones, two of which (AM00021 and AM00316) were from the above set of five A. mangium clones. An additional two clones (AC30003 and AC30020), were of another Acacia species, A. crassicarpa, deemed to be less susceptible to $C$. manginecans than A. mangium (Tarigan et al., 2013) and currently planted on peat soils in Sumatra by the same company. The last two clones of the set of six, AH80498 and AH80537, were of a hybrid being tested commercially by RAPP, A. auriculiformis $\mathrm{x}$ A. mangium. In view of the work of Trang et al. (2017), which showed a greater tolerance of A. auriculiformis towards the pathogen, hybrids involving that species were deemed to be of interest to study. In Vietnam, hybrids between A. auriculiformis and A. mangium are grown commercially and have been shown to have a range of susceptibility (Thu et al., 2012). However, they are not yet employed commercially by the large pulp and paper companies in Indonesia. The third experiment used 19 clones of $A$. mangium selected to have a range of susceptibility to the pathogen (Table 1). The clones came from a related study using a potted plant inoculation protocol that screened for tolerance/resistance to disease caused by Ceratocystis manginecans within a project supported by the Australian Centre for International Agricultural Research (Brawner et al., submitted).

Fungal isolates

The isolates of $C$. manginecans used in this study were obtained from A. mangium showing symptoms of ceratocystis wilt. Two of the isolates, CTA-128 and CTA-138, originated from different RAPP estates, Teso and Logas, respectively, both located in Riau Province, Sumatra, Indonesia. Both were isolated in 2012 and identified as $C$. manginecans, based on sequencing of the ITS ribosomal DNA (rDNA) and fragments of the $\beta$-tubulin and TEF genes (Tarigan et al., 2011a). CTA138 was inoculated into and re-isolated from an 
Table 1 Clones of Acacia mangium used in Experiment 3, each clone placed into an initial status group ranging from susceptible to highly tolerant based upon the susceptibilities to Ceratocystis manginecans displayed in a preliminary trial (data not presented)

\begin{tabular}{ll}
\hline Initial status & A. mangium clones \\
\hline Susceptible & A10(1), B22(10), D14(2), D76(1), E5(2) \\
Slightly tolerant & A71(3), B79(5), C71(7), D14(3), E2(5) \\
Moderately tolerant & A25, B7(1), C36, C48(1), D8(1) \\
Highly tolerant & A13, A32(3), AA38, B14
\end{tabular}

A. mangium seedling 3 weeks prior to its use, and then grown on malt extract agar (MEA) for 7 days at $22^{\circ} \mathrm{C}$. This freshly re-isolated culture derived from CTA-138 was differentiated as CTA-138* and served to compare the pathogenicity of an isolate that had been in continuous culture for 4 years with the same isolate after repassaging through a host plant. The third isolate, code C013, originated from Petak 323, Minas Rasau Kuning District, Riau, in 2014 and was identified as $C$. manginecans by CFBTI (unpublished results).

\section{Potted plant inoculation protocol}

Acacia cuttings were rooted in the nursery for 6 weeks and then planted in $20 \times 30 \mathrm{~cm}$ polybags. Mineral topsoil and $10 \mathrm{~g}$ of Osmocote ${ }^{\circledR}$, a slow release fertilizer, were added to each bag. The plants in polybags were set out in an open area dedicated to pot trials and adjacent to greenhouses at RAPP headquarters in Kerinci, Riau Province. All plants were maintained for 3 months under conditions favourable for healthy growth before inoculating with $C$. manginecans.

Inoculation of potted plants was carried out by one of two methods following a previously published protocol (Van Wyk et al., 2010). For both methods, stems that ranged from 54 to $134 \mathrm{~cm}$ initial height were wounded approximately $20 \mathrm{~cm}$ above soil level using a sterile scalpel. For the first method, mycelium for inoculum was taken from the edge of the culture plate to ensure it was actively growing. A plug of $C$. manginecans was then placed into the wound with the mycelium facing the cambium. For the second method, inoculum was prepared by harvesting conidia from 7-day-old $C$. manginecans cultures following the procedure of Baker et al. (2003). The culture was flooded with $10 \mathrm{~mL}$ sterile distilled water and then scraped with a sterile spatula to suspend the spores. The suspension was then filtered through sterile Miracloth (Sigma Aldrich) and the concentration of conidia estimated using a haemocytometer. Conidial suspensions were diluted to a concentration of 2 $\times 10^{5}$ conidia/mL and a $10 \mu \mathrm{L}$ aliquot was pipetted into the wound in the stems. Control treatments of sterile agar plugs or sterile distilled water were applied as for fungal inoculum treatments. The treated wounds were then sealed with wrapping tape to avoid contamination and desiccation.

Inoculated plants ranging from 54 to $134 \mathrm{~cm}$ initial height were maintained for 5 weeks and monitored for disease symptoms. Lesions were indicated by sapwood discolouration which shows as dark reddish brown to purple discolouration in both external (bark) and internal (sapwood) tissues. Starting from 3 weeks after inoculation, the lengths of external lesions were recorded weekly to five weeks after inoculation, and internal lesions were measured after debarking the stems in the fifth week after inoculation. An external or internal discolouration index (DI) was then calculated as the percentage of lesion length per total stem length.

\section{Stem segment inoculation protocol}

Stem segments of approximately $35 \mathrm{~cm}$ length by $3 \mathrm{~cm}$ diameter were harvested from the main stem of 6-monthold potted plants of the Acacia species and clones to be screened. Preliminary trials to avoid desiccation and contamination in the stem segment procedure had shown that covering both ends of the stems with wax was more effective than the other methods tested, viz., covering the ends of the stems with moistened cotton-wool or paper tape or sitting the segments in moist sand. Waxing the stem segment ends slowed desiccation for at least $65 \%$ of the stems but only for a maximum of 3 weeks after inoculation. When the inoculated stem segments were placed in sterile clear plastic bags to further slow desiccation, contaminant fungi quickly obscured the surface of the lesions and it was difficult to assess external lesion development beyond 2 weeks after inoculation.

Prior to inoculation, stem segments with waxed ends were wounded using a sterilized $5 \mathrm{~mm}$ diameter cork borer. A plug of $C$. manginecans mycelium was then taken from the edge of the culture and inserted with the mycelium facing directly into the wound. The inoculated wound was then wrapped with $24 \mathrm{~mm}$ wide paper masking tape (Kingstone-Tape.com, Indonesia). Sterile agar plugs were applied in the same manner to the control samples, which were not inoculated. Inoculated and 
control stem segments were incubated at room temperature on the laboratory bench for 3 weeks. External lesion measurements were recorded every 7 days after inoculation for 3 weeks. Internal lesions were measured in the third week by removing the bark of the stem segment. A discolouration index (DI) was calculated as the percentage of longitudinal discolouration per total stem segment length.

Phyllode inoculation protocol

Preliminary tests carried out with phyllodes of different ages collected from young trees planted in the soil in an area used for resistance screening at RAPP, Kerinci, Sumatra showed little difference in lesion development among phyllodes of different ages (data not shown). For the current set of experiments, phyllode lengths ranged between 8 and $33 \mathrm{~cm}$. The phyllode bases were quickly wrapped in sterile moistened cotton wool and stored at $4{ }^{\circ} \mathrm{C}$ in a plastic bag prior to inoculation. The maximum storage time prior to inoculation was $24 \mathrm{~h}$. If this storage time was exceeded, symptoms of desiccation (phyllode tip browning) unrelated to lesion development were observed.

Conidial suspensions were prepared as described for the inoculation of potted plants. After wounding with a sterile needle, a $10 \mu \mathrm{L}$ aliquot of conidial suspension or sterile distilled water (control) was pipetted into the middle of the surface of the phyllode. The phyllodes were put into sterile, clear plastic bags with sterile, moistened cotton-wool to avoid desiccation and maintained at $25{ }^{\circ} \mathrm{C}$ until the disease symptoms appeared. The length of the lesion and the discolouration in the phyllodes were observed and measured daily for up to 3 weeks after inoculation. A discolouration index was calculated as the percentage of discolouration length per total phyllode length.

\section{Comparison of screening protocols}

The three screening protocols, viz. potted plants, stem segments and phyllodes, were compared within three distinct experiments, which will now be described in turn.

\section{Experiment 1}

The responses to 3 isolates of $C$. manginecans (CTA128, CTA-138 and CTA-138*) by five clones of A. mangium were compared using the three inoculation protocols (see Table 2). The potted plant trial was set up as a completely randomized design with eight treatments applied to each of the five clones. The treatments were made up of the isolates (CTA-128 and CTA-138) or the re-isolated culture (CTA-138*) used both as mycelial plugs and as conidial suspensions, plus two control treatments, sterile water agar plugs and sterile distilled water. Each experimental unit contained 20 whole Acacia rooted cuttings, for a total of 800 plants overall. For the subsequent statistical analyses, mean values were taken over the 20 plants to avoid pseudoreplication. As no lesions or necroses were observed for any control treatment, those experimental units were not included in the analysis of variance, and the number of experimental units $\mathrm{N}=30$ in Table 2 reflects this omission. For the stem segment protocol, the five clones were used with four inoculation treatments consisting of the mycelium of the three isolates CTA-128, CTA-138 and CTA-138* and with sterile water agar plugs as a control (the conidial suspension was omitted). Each treatment was applied to 20 stem segments, for a total of 400 segments overall. As with the potted plant protocol, mean values were taken over the 20 stem segments to avoid pseudoreplication. For the phyllode protocol the five clones were inoculated with conidial suspensions of CTA-128, CTA-138 and CTA-138*, and with sterile distilled water as a control. With 20 phyllodes used for each of the 20 treatment combinations, 400 phyllodes were employed overall. As with the other two protocols, mean values were taken over the 20 phyllodes to avoid pseudoreplication.

\section{Experiment 2}

The responses to a single isolate of $C$. manginecans (CTA-138*) by six clones of Acacia species or hybrids were compared using the potted plant, stem segment and phyllode inoculation protocols (see Table 2). The potted plant trial was set up as a completely randomized design with five replicates, each replicate having the six clones in combination with two different fungal inoculum types (mycelium and conidia) of the isolate CTA-138* and included two controls (sterile water agar and sterile distilled water). There were 15 plants per experimental unit. The stem segment protocol used the same six Acacia clones with the inoculation treatment being the mycelium of CTA-138* and with sterile agar plugs as a control. There were four replicates, with each treatment applied to 20 stem segments from each of the six clones. 
The phyllode protocol used a conidial suspension of CTA-138* for the inoculation treatment and sterile distilled water as a control treatment. Each treatment was applied to 20 phyllodes from each of the six clones in each of four replicates. As in Experiment 1, mean values taken over individual potted plants, stem segments, or phyllodes became the response variable to avoid pseudoreplication when analysis of variance was performed. As no lesions or necroses were observed for the control treatments, those experimental units were not included in the analysis of variance, and the number of experimental units $\mathrm{N}$ shown in Table 2 do not include these controls.

\section{Experiment 3}

This experiment was concerned with clones of A. mangium, with 19 clones tested, comprising a range of susceptibilities to ceratocystis wilt and canker disease. Based upon a previous assessment conducted at PT Arara Abadi, Sinarmas Forestry, the 19 clones were classified into four groups, viz. highly tolerant, moderately tolerant, slightly tolerant and susceptible (Table 1). Only two of the three protocols (whole potted plants and phyllodes) that were used in Experiments 1 and 2 were employed in this experiment. Also, a different isolate of C. manginecans (code C013 sourced from Petak 323, Minas Rasau Kuning District, Riau, Indonesia, in 2014) was used. For the protocol using whole potted plants, mycelial plugs were used for inoculation as in the preceding experiments. For the protocol involving phyllodes, a conidial suspension was used for inoculating five phyllodes from each of the 19 clones. Mean DI per clone of A. mangium was determined 5 days after inoculation and the assays repeated with another set of the same 19 clones.

Statistical analysis

Differences in DI's among Acacia clones and species tested in response to mycelial and conidial inoculum from stored and newly re-isolated cultures were tested using analysis of variance (ANOVA) employing the general linear model (GLM) procedure of SAS (SAS system v 9.4; SAS Institute Inc., Cary, NC, USA) and Fisher's LSD test. Attention was focussed on ANOVAs carried out at each individual time of observation, as there was particular interest in the time of the first appearance of symptoms for each of the screening 
protocols. Due to the lack of replication for the potted plant protocol of Experiment 1, the 3-factor interaction (clones $\times$ isolates $\times$ inoculation method) was used as the error term for carrying out the ANOVA. All other protocols in all three experiments had at least two biological replicates (see Table 2).

\section{Results}

Experiment 1

\section{Potted plants}

No lesions emerged on the stems of whole potted plants of five clones of $A$. mangium which were inoculated with sterile distilled water or sterile water agar plugs and these results were excluded from the statistical analysis. For those treatments for which lesions were observed, the discolouration or sap streaks on inoculated stems of potted Acacia seedlings first appeared ca. 7 days after inoculation. In general, internal lesions occurred continuously along the stem, whereas external lesions were often intermittent (Fig. 1). Three to 5 weeks after inoculation, there was an approximate 3 -fold variation in the external DI's between the most susceptible A. mangium clone, AM00021, and the least susceptible clone AM00870, and an approximate 2-fold variation in internal lesions between those same two clones (Fig. 2). Isolate CTA-128, from a different geographic region, resulted in the smallest external and internal DI's at all assessment dates relative to isolates CTA-138 and CTA138*. ANOVA confirmed that clone $(\mathrm{P}=0.0003)$ and isolate $(\mathrm{P}<0.0001)$ were significant factors in determining internal and external lesion length at 5 weeks after inoculation, but inoculum type and any interactions were not. There was no statistically significant difference between the DI's produced by $C$. manginecans isolates CTA-138 (stored in culture) and CTA-138* (freshly re-isolated) at any of the assessment dates, the latter two isolates producing similar external and internal DI's (Table 3). Looking at each clone independently, the only significant differences in lesion length produced by these two isolates were transient; at 3 weeks after inoculation the external lesion produced by $\mathrm{C} 138$ on AM00868 was greater than that produced by $\mathrm{C} 138^{*}$ and at 4 weeks the external lesion produced on AM00021 was greater than that produced by $\mathrm{C} 138$ (Supplementary Fig. S1). Irrespective of the clone of A. mangium, inoculation with spores produced
Fig. 1 The discolouration on the stem of a potted Acacia plant caused by Ceratocystis manginecans. The external discolouration tended to have gaps between the lesions, A, whereas the internal lesions tended to grow continuously along the stem, $\mathbf{B}$
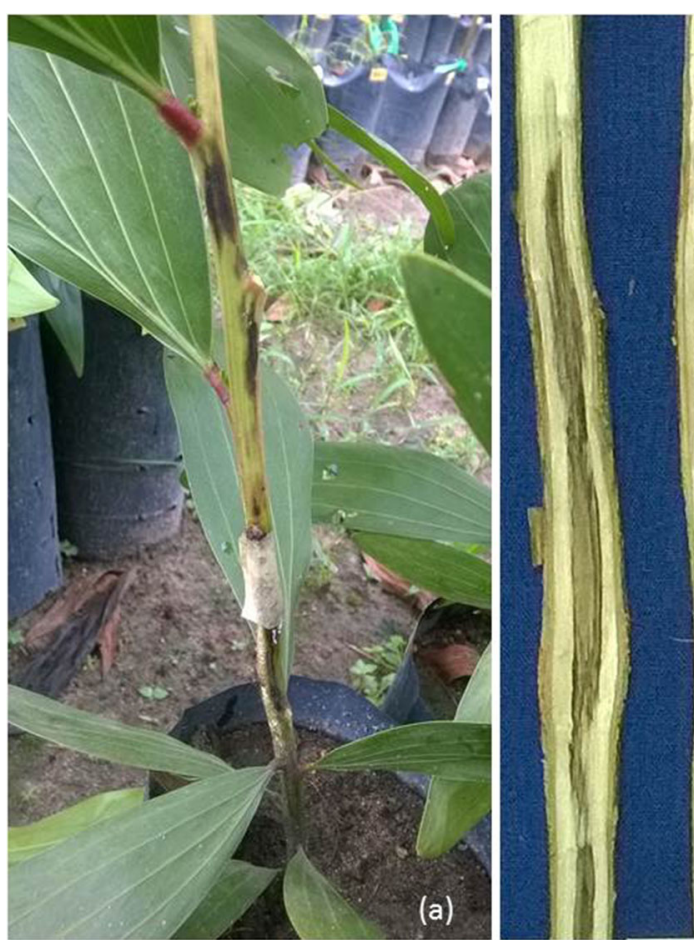
Fig. 2 Experiment 1 - Potted plants inoculated with C. manginecans isolates CTA128, CTA-138 and CTA-138*. Values shown for each of five clones of Acacia mangium are mean $( \pm$ s.e. $)$ discolouration index DI (\%) averaged over the 3 isolates and 2 inoculation methods 3-5 weeks after inoculation for external lesions and 5 weeks after inoculation for internal lesions $(n=6)$

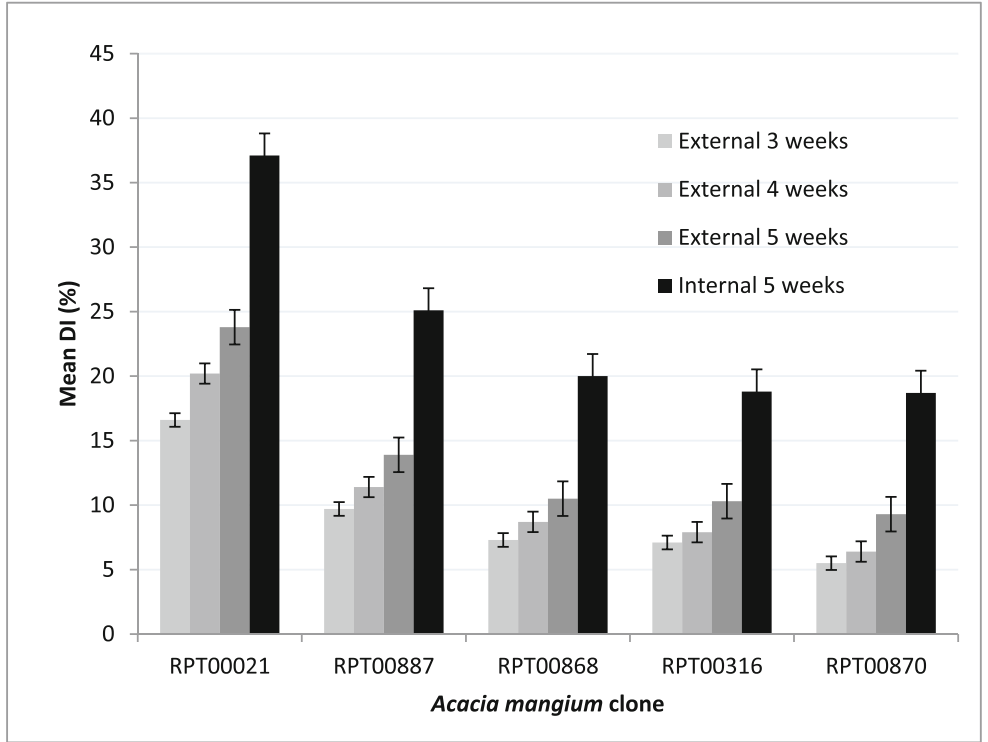

significantly lower $(\mathrm{P}<0.05)$ DI's compared with mycelium plugs in the earliest assessment (3 weeks after inoculation), but neither the external nor internal lesions were significantly different at the assessment 5 weeks after inoculation (Table 4).

\section{Stem segments}

The external lesions on five clones of $A$. mangium appeared 7 days after inoculation but were usually only observed clearly at 14 days after inoculation. Even though both tips of stems were covered with wax, the stems still dried readily. Other contaminant fungi also emerged on the stem surfaces. These two problems resulted in slower development of lesions on the stem, causing unclear early disease symptoms and then limiting the duration of lesion measurement to 2 weeks only.
Differences in the extent of lesion development in stem segments among the five clones of $A$. mangium were relatively small (Fig. 3), with the maximum DI for external lesions being $6.4 \%$ and that for internal lesions being $11.1 \%$ for AM00870, a clone that had a lower external DI relative to two others when whole potted plants were used (Fig. 2). The DI's for internal lesions (Fig. 3b) were significantly higher than for external lesions (Fig. 3a). Isolates $\mathrm{C} 138$ and $\mathrm{C} 138^{*}$ produced comparable DIs that were only significantly different for clone AM00887 (Supplementary Fig. S2), with C138* producing a longer lesion.

\section{Phyllodes}

Phyllodes of clones susceptible to $C$. manginecans displayed necrotic symptoms 5 days after inoculation

Table 3 Comparison of discolouration indices (DI's) for three isolates of Ceratocystis manginecans inoculated to potted A. mangium plants at 3, 4 and 5 weeks after inoculation (WAI)

\begin{tabular}{|c|c|c|c|c|}
\hline \multirow[t]{2}{*}{ Isolate } & \multicolumn{3}{|c|}{ Mean external DI $(\%)$} & \multirow{2}{*}{$\begin{array}{l}\text { Mean internal DI }(\%) \\
5 \mathrm{WAI}\end{array}$} \\
\hline & $3 \mathrm{WAI}$ & 4WAI & 5WAI & \\
\hline CTA-128 & $5.4 \pm 0.4^{\mathrm{b}}$ & $5.3 \pm 0.6^{\mathrm{b}}$ & $6.1 \pm 1.0^{\mathrm{b}}$ & $13.7 \pm 1.3^{\mathrm{b}}$ \\
\hline CTA-138 & $11.8 \pm 0.4^{\mathrm{a}}$ & $13.8 \pm 0.6^{\mathrm{a}}$ & $17.8 \pm 1.0^{\mathrm{a}}$ & $30.4 \pm 1.3^{\mathrm{a}}$ \\
\hline CTA-138* & $10.5 \pm 0.4^{\mathrm{a}}$ & $13.7 \pm 0.6^{\mathrm{a}}$ & $16.8 \pm 1.0^{\mathrm{a}}$ & $27.7 \pm 1.3^{\mathrm{a}}$ \\
\hline
\end{tabular}

DI's are expressed as mean values \pm standard error (SE). Different letters $(a, b)$ in the same column indicate statistically significant differences between pairs of three isolates at that assessment (pairwise t-test, $\alpha=0.05$ ) 
Table 4 Discolouration indices (DI's) for the effect of two forms of inoculum on the stems of potted plants at 3, 4 and 5 weeks after inoculating (WAI) with isolates of C. manginecans

\begin{tabular}{|c|c|c|c|c|}
\hline \multirow[t]{2}{*}{ Inoculum form } & \multicolumn{3}{|c|}{ Mean external DI (\%) } & \multirow{2}{*}{$\begin{array}{l}\text { Mean internal DI }(\%) \\
5 \text { WAI }\end{array}$} \\
\hline & 3 WAI & 4 WAI & 5 WAI & \\
\hline \multicolumn{5}{|l|}{ Experiment 1: } \\
\hline Mycelium & $10.8 \pm 0.3^{\mathrm{a}}$ & $12.5 \pm 0.5^{\mathrm{a}}$ & $15.4 \pm 0.8^{\mathrm{a}}$ & $26.1 \pm 1.0^{\mathrm{a}}$ \\
\hline Spores & $7.7 \pm 0.3^{\mathrm{b}}$ & $9.4 \pm 0.5^{b}$ & $11.7 \pm 0.8^{\mathrm{a}}$ & $21.8 \pm 1.0^{\mathrm{a}}$ \\
\hline \multicolumn{5}{|l|}{ Experiment 2: } \\
\hline Mycelium & $7.7 \pm 0.7^{\mathrm{a}}$ & $9.9 \pm 0.8^{\mathrm{a}}$ & $13.0 \pm 0.8^{\mathrm{a}}$ & $21.2 \pm 0.9^{\mathrm{a}}$ \\
\hline Spores & $5.6 \pm 0.7^{b}$ & $9.1 \pm 0.8^{\mathrm{a}}$ & $12.3 \pm 0.8^{\mathrm{a}}$ & $19.1 \pm 0.9^{\mathrm{a}}$ \\
\hline
\end{tabular}

Experiment 1 used five clones of A. mangium (AM00021, AM00316, AM00868, AM00870 and AM00887) and three isolates (CTA-128, CTA-138, CTA-138*). Experiment 2 used two clones each of A. mangium, A. crassicarpa and a hybrid between A. auriculiformis and A. mangium, but only the rejuvenated isolate CTA-138*. DI's are expressed as mean values \pm standard error (SE). Different letters (a,b) indicate statistically significant differences between the two inoculum types, mycelium vs. spore suspension (t-test, $\alpha=0.05)$

with conidial suspensions, the lesion approaching the phyllode apex for some phyllodes about 2 weeks after the first appearance of the symptoms (Fig. 4). By 3 weeks after inoculation, mean DI's for all five A. mangium clones were $40-55 \%$ and showed a similar pattern of response among clones (Fig. 5a) and among C. manginecans isolates (Fig. 5b) to the results for potted plants. Results for $\mathrm{C} 138$ and $\mathrm{C} 138^{*}$ were not statistically different except for clone AM00868 at 6 and 10 days after inoculation, AM00887 at 6 days after
Fig. 3 Experiment 1 - Stem segments inoculated with C. manginecans isolates CTA128, CTA-138 and CTA-138*. Values shown for each of five clones of Acacia mangium are mean (+s.e. based upon a pooled variance) discolouration index DI (\%) 2 weeks after inoculation, averaged over 2 replicates: $\mathbf{A}$ External lesions; B Internal lesions
A

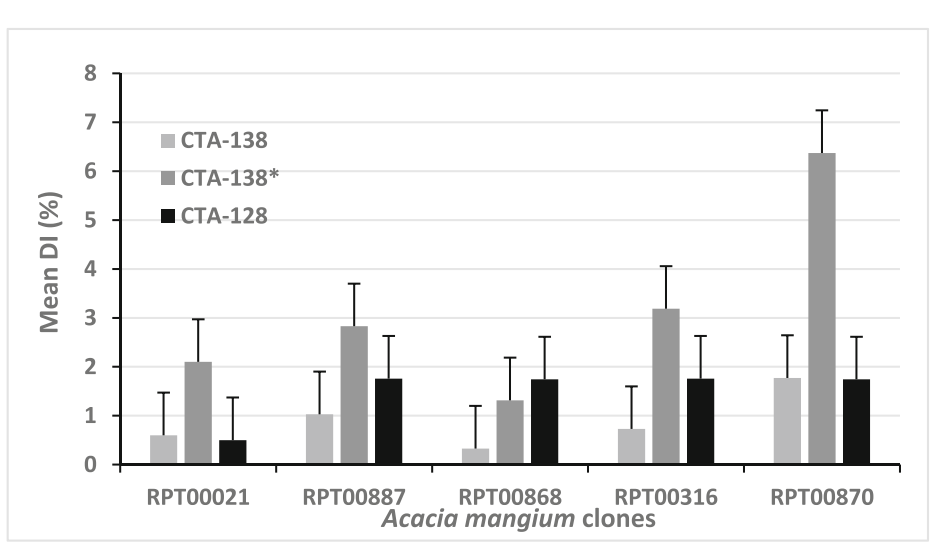

B

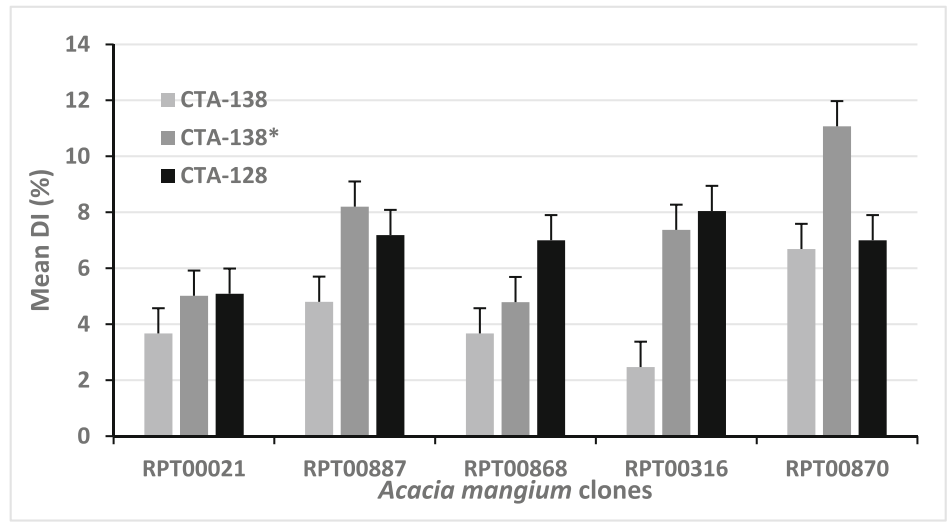



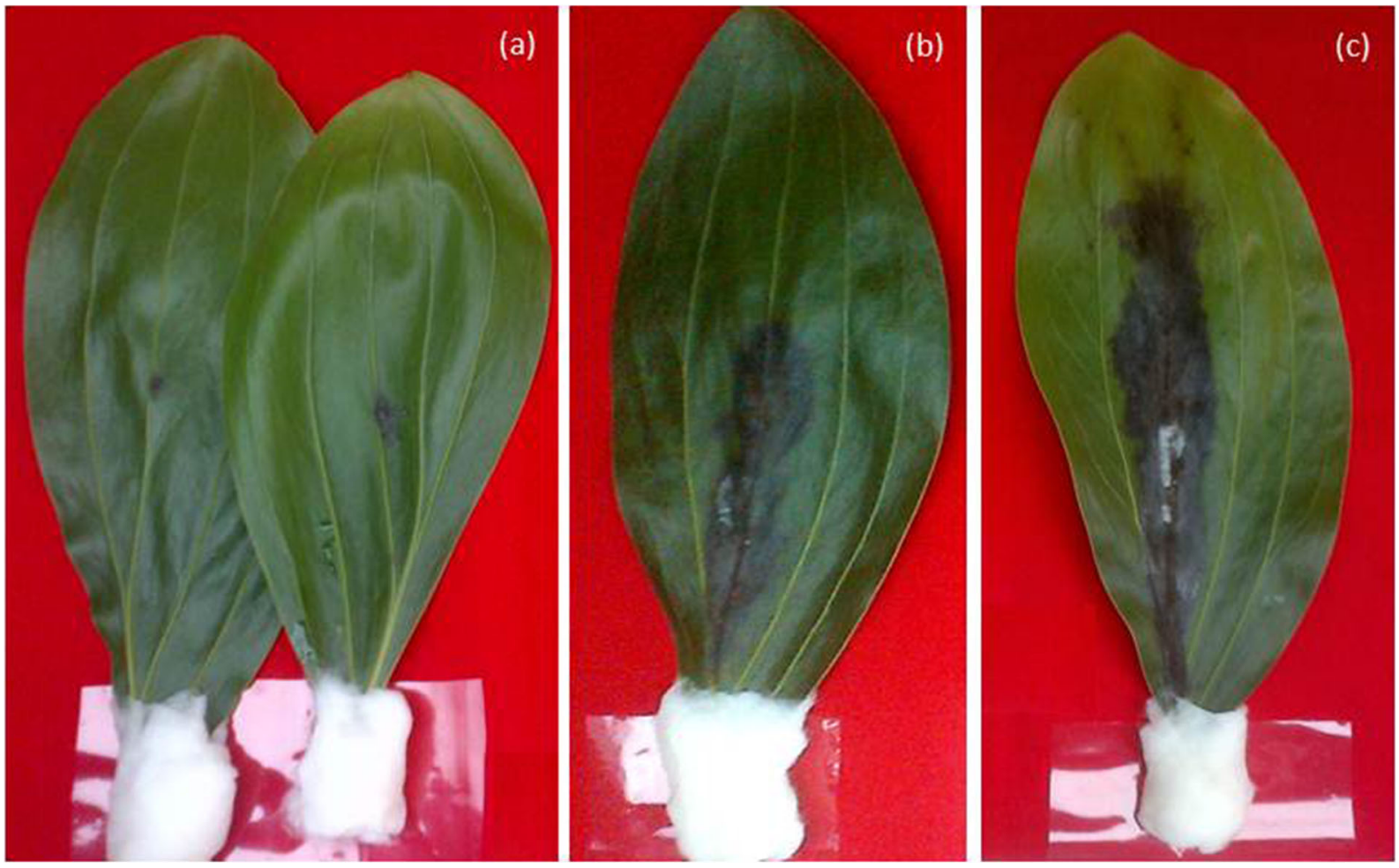

Fig. 4 Necrotic development on phyllodes of A. mangiumA 5, B 10 and C 14 days after inoculating with freshly re-isolated Ceratocystis manginecans CTA-138*

inoculation and AM00870 at 14 and 19 days after inoculation (Supplementary Fig. S3).

\section{Experiment 2}

\section{Potted plants}

A. mangium clones (AM00021 and AM00316) recorded considerably higher DI's (\%) for external lesions than $A$. crassicarpa (AC30003 and AC30020), with the Acacia hybrid (AH80498 and AH80537) being intermediate after inoculation with a conidial suspension of $C$. manginecans isolate CTA-138* (Fig. 6, Supplementary Fig. S4). Visual observation showed that over $50 \%$ of the ramets of the most susceptible clone (AM00021) were yellowing and wilting at 4 weeks after inoculation and had started to dry out. These plants were dead at 5 weeks after inoculation.

Irrespective of Acacia species or clone, inoculation with spores produced significantly lower $(\mathrm{P}<0.05)$ DI's compared with mycelium plugs in the earliest assessment (3 weeks after inoculation), but neither the external nor the internal lesions were significantly different at the assessment 5 weeks after inoculation (Table 4).

\section{Stem segments and phyllodes}

As in experiment 1, external and internal lesions appeared on stem segments 7 days after inoculation with isolate CTA-138*. Lesions developed further in the following 7 days, after which the stems tended to dry out. At 14 days after inoculation, results were consistent with the findings for potted plants; that is, both clones of A. crassicarpa had lower DI's compared with the two clones of A. mangium 14 days after inoculation. The DI's of the Acacia hybrid clones were intermediate (Fig. 7, Supplementary Fig. S5).

Similarly, the phyllodes of both clones of $A$. crassicarpa exhibited a lower level of necrosis compared with the clones of A. mangium and the Acacia hybrid, with clone AM00021 of A. mangium being affected most severely (Figs. 8, 9, Supplementary Fig. S6). The two clones of the Acacia hybrid (AH80498 and 
Fig. 5 Experiment 1 - Phyllodes inoculated with $C$. manginecans isolates CTA-128, CTA-138 and CTA-138*. Values shown are mean $( \pm$ s.e. based upon a pooled variance) discolouration index DI (\%) 1-3 weeks after inoculation of five clones of Acacia mangium: $\mathbf{A} A$. mangium clones averaged over the three isolates and two replicates $(n=6)$;

BC. manginecans isolates averaged over the five clones and two replicates $(\mathrm{n}=10)$
A

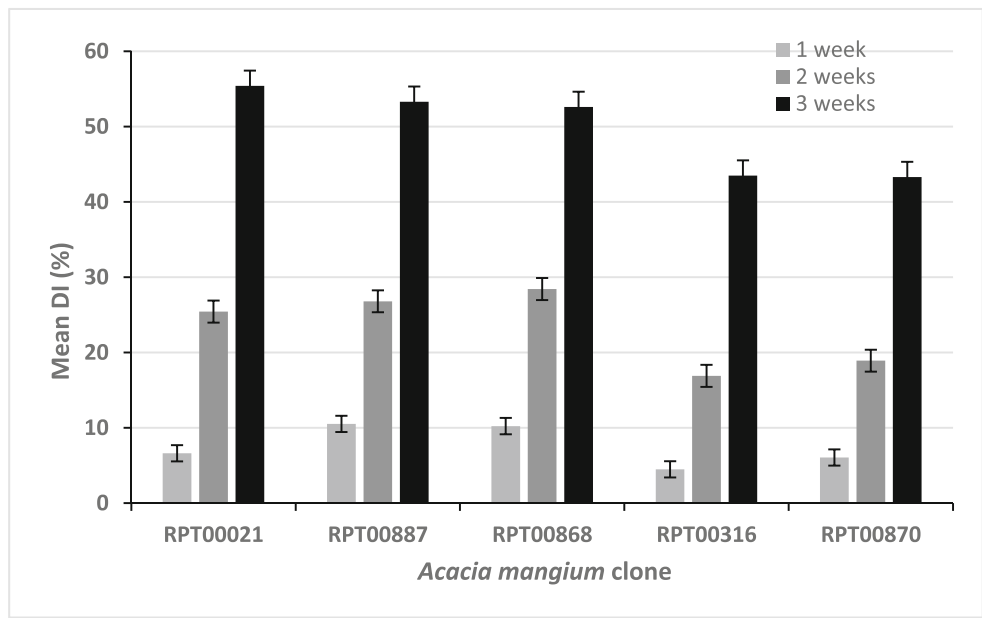

B

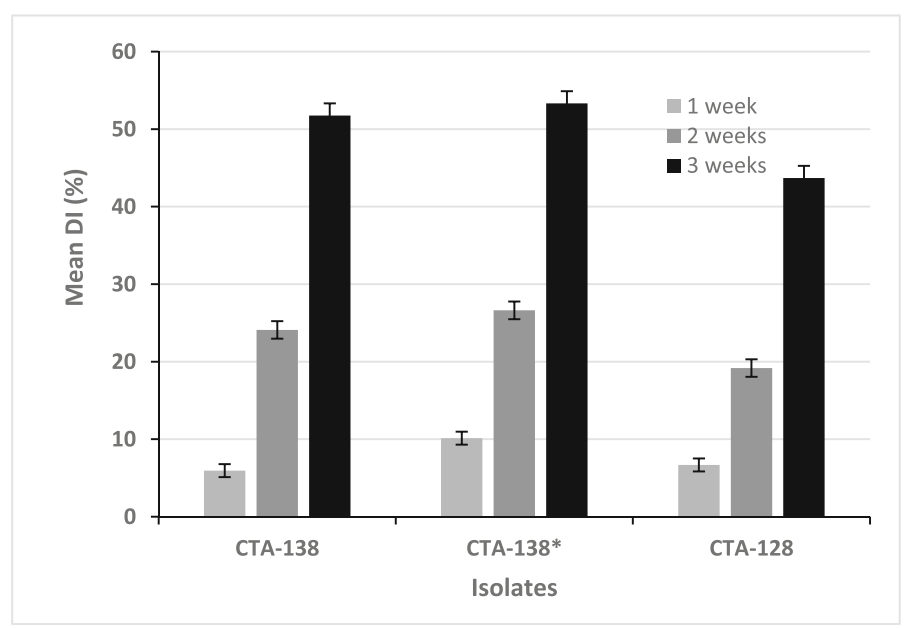

AH80537) were intermediate between the clones of the two pure species, and significantly different from them $(\mathrm{P}<0.05)$ at 18 days after inoculation with a conidial suspension of C. manginecans, isolate CTA-138*.

\section{Experiment 3}

\section{Potted plants}

The three least susceptible clones amongst the 19 clones of A. mangium were A13, AA38 and A32(3), with respect to both the development of external lesions (Fig. 10a) and internal lesions (Fig. 10b) 3 weeks after inoculation with $C$. manginecans isolate C013. These three clones all had a mean DI (\%) of less than $50 \%$ for both external and internal lesions. These clones were three of the four clones ranked previously as highly tolerant to ceratocystis wilt and canker disease (Table 1).

\section{Phyllodes}

The 19 clones of $A$. mangium exhibited a wide range of responses 5 days after inoculation of phyllodes with $C$. manginecans isolate $\mathrm{C} 013$ (Fig. 10); the DI's were in the range $0.8-28.3 \%$. After 2 weeks, seven clones had a DI of $100 \%$ in one replicate and eight clones had a DI of $100 \%$ in the other replicate (data not shown). The three clones of A. mangium found to be least susceptible as potted plants (Fig. 9) were also among the four to six clones with the lowest phyllode DI's (Fig. 11). For these three clones, necrosis extended to less than $2.3 \%$ of the length of the phyllode in each replicate. B14, classed as 
Fig. 6 Experiment 2 - Potted plants inoculated with C. manginecans freshly reisolated CTA-138*. Values shown are discolouration index DI (\%) means ( \pm s.e.) averaged over 5 replicates for external lesions 3-5 weeks after inoculation (3WAI, 4WAI, 5WAI) and internal lesions 5 weeks after inoculation (5WAI) on six clones of Acacia species or hybrids: A Mycelium only; B Spores only

\section{A Mycelium only}

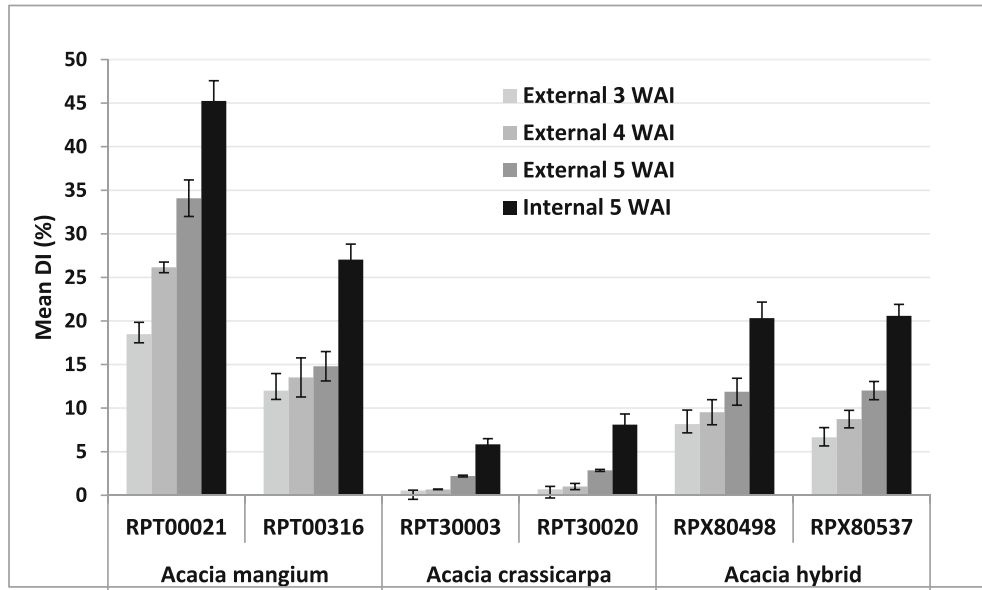

B Spores only

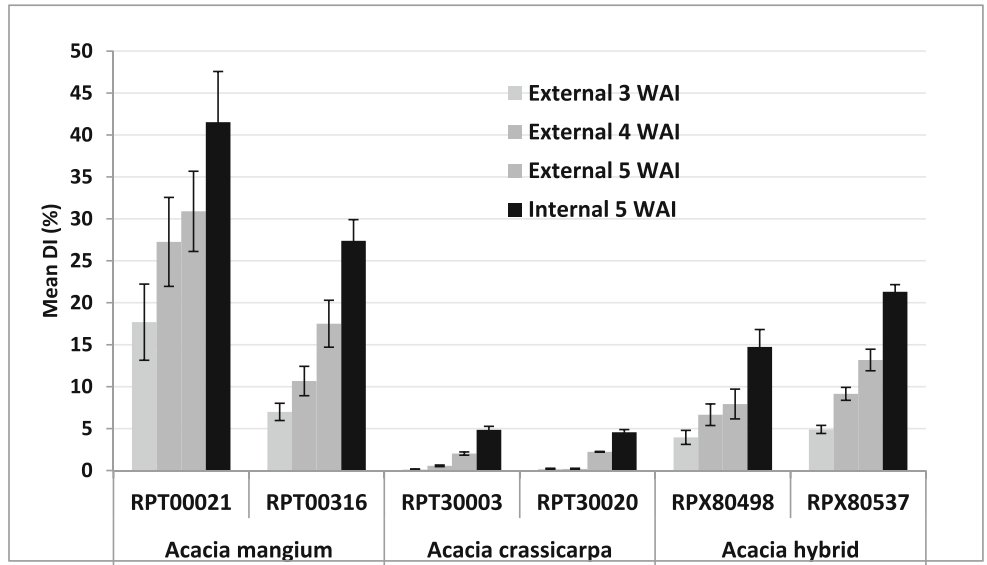

highly tolerant in previous screenings (Table 1) had a DI of 2.1 or $5.8 \%$ depending on the replicate. Only one of the moderately tolerant clones in the initial trial, B7(1), displayed relatively low DI's on phyllodes.
Fig. 7 Experiment 2 - Stem segments inoculated with

C. manginecans freshly reisolated CTA-138*. Values shown are discolouration index DI $(\%)$ means ( \pm s.e. based upon a pooled variance) averaged over 4 replicates for external and internal lesions 14 days after inoculation, from six clones of Acacia species or hybrids

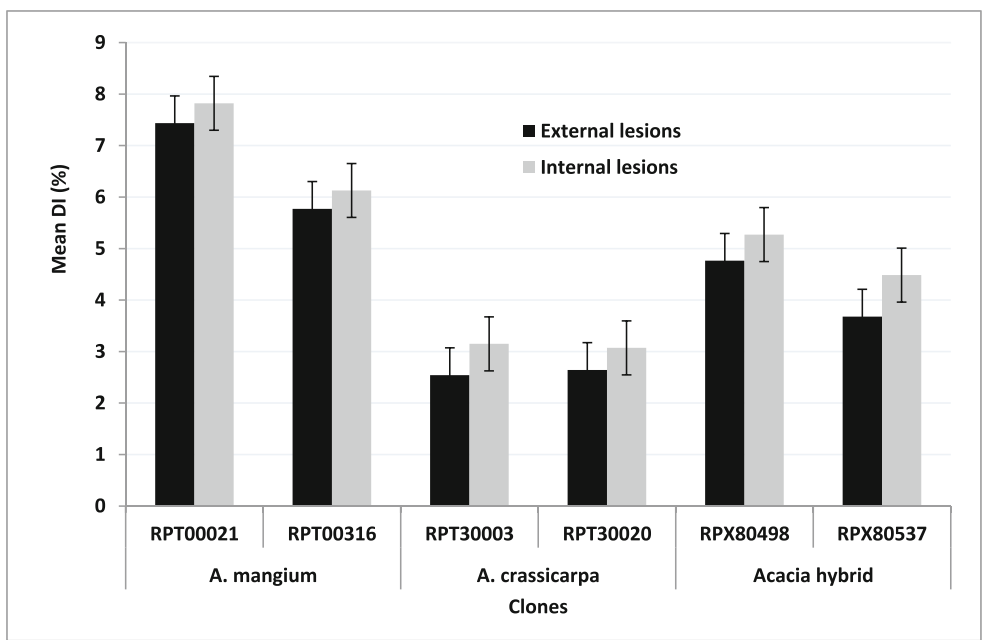




\section{Discussion}

Field trials are an important component of breeding programs, but rapid preliminary screening can expedite selection of plant accessions that are less susceptible to disease by excluding the most susceptible germplasm before the field trial stage. Use of potted plants under greenhouse conditions provides such an alternative (Luiz et al., 2020) and a basis from which to develop more efficient screening systems such as the phyllode inoculation assay evaluated here. Preliminary screening of potted seedlings is widely used in Indonesia and Vietnam (Chi et al., 2019; Brawner et al., 2020).

The inoculation technique on the stems of potted plants resulted in C. manginecans producing lesions on the bark 2 weeks after inoculation and also revealed variation in tolerance among five clones of A. mangium. This result indicates that there is a potential for genetic improvement by selecting material that is less susceptible to ceratocystis wilt and canker disease. This procedure has been used in many studies to evaluate the pathogenicity of isolates of Ceratocystis species or the

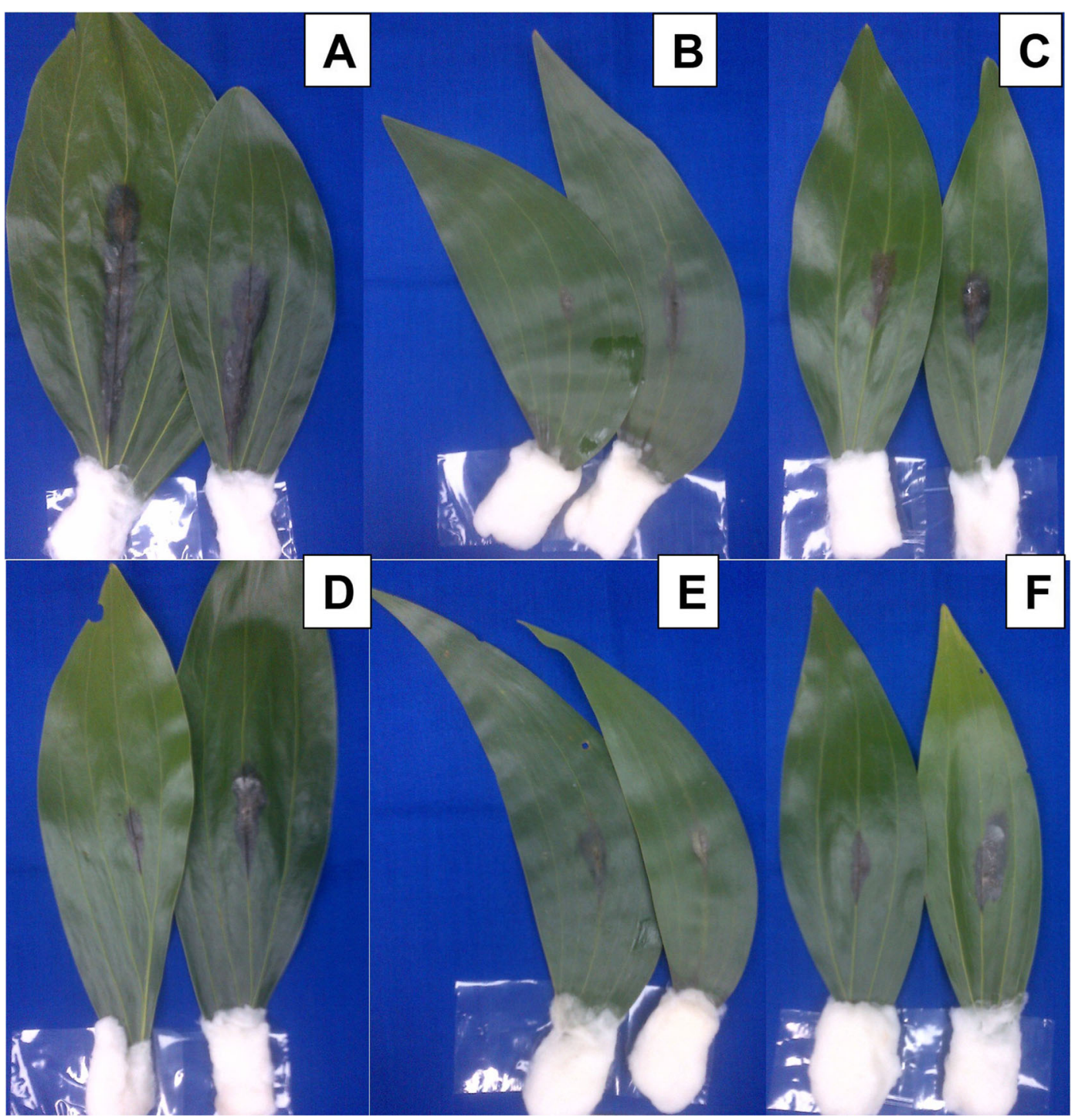

Fig. 8 Necrotic development on phyllodes of AA. mangium AM00021, BA. crassicarpa AC30003, CAcacia hybrid AH80498, DA. mangium AM00316, EA. crassicarpa AC30020, FAcacia hybrid AH80537 5 days after inoculation with Ceratocystis manginecans 
Fig. 9 Experiment 2 - Phyllodes inoculated with C. manginecans freshly re-isolated CTA-138*. Values shown are discolouration index DI (\%) means $( \pm$ s.e.) averaged over 4 replicates from phyllodes taken from six clones of Acacia species or hybrids at five, ten, 14 or 18 days after inoculation (DAI)

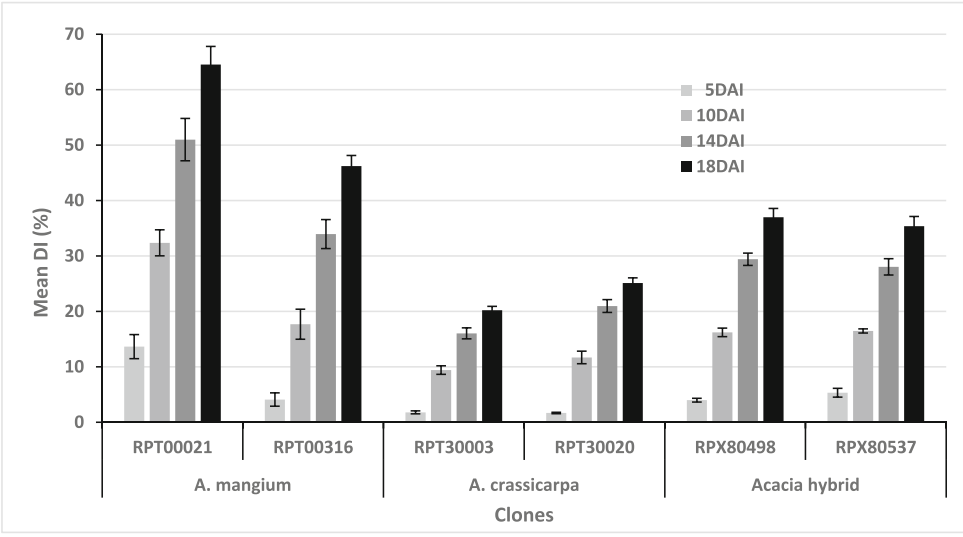

resistance of plant species or genotypes to wilt and canker disease, although it is argued that greenhouse experiments may yield different results to field experiments (Van der Westhuizen et al., 1992). However, when compared with a field inoculation test, potted plant inoculation is less costly and more time-efficient, and avoids introducing pathogen inoculum into the field, as well as having the potential to be used for evaluating the pathogenicity of non-native isolates (Van Wyk et al., 2010). Nevertheless, the potted plant procedure is time consuming, as the procedure took ca. 18 weeks to screen the Acacia trees, starting from the preparation of cuttings through to the inoculation and the assessment of the plant tolerance or susceptibility. At 5 weeks after inoculation, the plants were harvested and assessed for internal lesions, as most of those that had indicated susceptibility to ceratocystis disease showed symptoms of wilt or drying, indicating that maximum infection had occurred by that time. Although trials with potted plants are faster than field trials, a more rapid test is needed to expedite the screening process when assessing a large number of plants. In view of the low level of exploitable resistance in A. mangium to ceratocystis disease (Brawner et al., 2015), it is anticipated that it will be necessary to screen a very large number of genotypes to establish a breeding program to identify useful levels of disease tolerance.

One of the alternatives to whole potted plants was to use small-sized stem segments. However, it proved difficult to avoid desiccation and contamination in the stem segments used for inoculation experiments. The available time window for assessing the lesions on the stem segments was shortened to a maximum of 23 weeks after inoculation. Low water availability due to evaporation in the phloem and cambium of the stem segments may inhibit spore germination or mycelial growth, as the phloem and cambium may be the pathway used by $C$. manginecans in the colonization phase, as it is for C. fimbriata in aspen (Zalasky, 1965). Preliminary tests to prevent desiccation using wax, moistened cotton wool or sand showed that wax was the most effective for controlling water evaporation. However, it may prevent desiccation for a maximum of only 2 weeks due to evaporation through the entire stem segment surface. The size of the stem segments also may have contributed to increasing desiccation, and stem segments larger than the $3 \mathrm{~cm}$ diameter ones used in this experiment may be needed to delay desiccation, thereby providing adequate time to assay the lesions on the stem segments. A previous inoculation study using $40 \mathrm{~cm}$ long bolts from six-year-old Eucalyptus grandis successfully avoided desiccation and gave results that correlated with field inoculation (Van Wyk et al., 2010). In our Experiments 1 and 2, however, although it was shown that the stem segment inoculation protocol separated Acacia clones for disease susceptibility, the discrimination was not as clear as in the inoculation procedures using potted plants or phyllodes. Therefore, the inoculation protocol for stem segments was not used in Experiment 3.

The ranking of clones in experiment 3 , based on either potted plant or phyllode assays, did not exactly reproduce the ranking from the previous trial and this exemplifies the variability that has previously been observed in interactions between A. mangium and C. manginecans (Brawner et al., submitted). This variability may relate to the size of the wound, plant nutrition, environmental factors or epigenetic modifications (Alonso et al., 2018). Nonetheless, with the exception of clone B14, the clones previously classed as tolerant 
Fig. 10 Experiment 3 - Potted plants inoculated with C. manginecans code $\mathrm{C} 013$. Values shown are discolouration index DI (\%) means (+ s.e.) averaged over 8 replicates at 3 weeks after inoculation for each of 19 A. mangium clones: A external lesions; B internal lesions. Clones highlighted in grey are the three most tolerant to infection in this trial
A External lesions

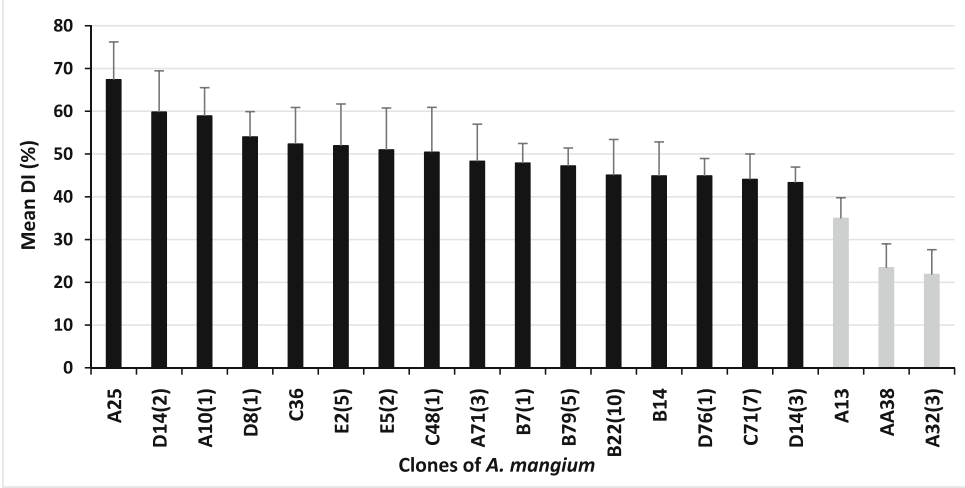

B Internal lesions

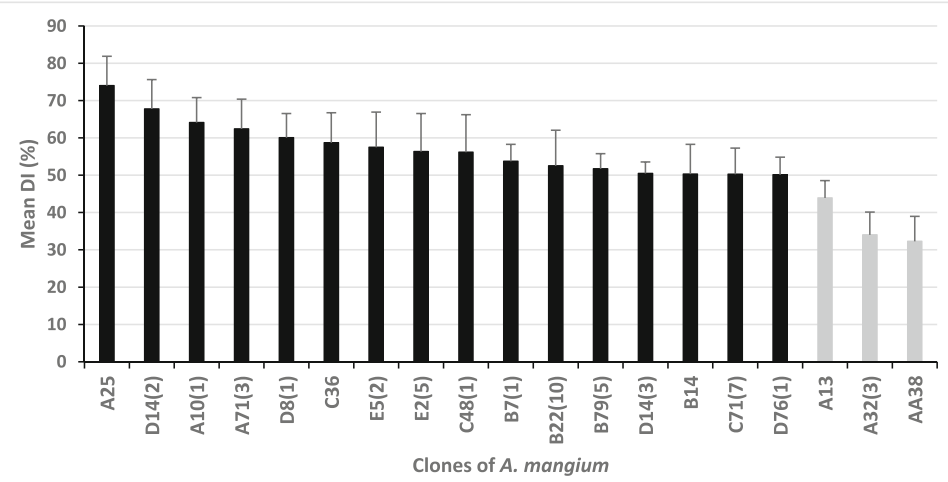

were consistently placed at the tolerant end of the spectrum and DIs were significantly lower than the most susceptible clones in each test. The low level of statistical separation among the majority of the clones is symptomatic of the low levels of genetic disease tolerance in A. mangium (Brawner et al., 2015) however discrimination was robust when a broader range of tolerance was available as in experiment 2 , which compared clones from three different species.

The inoculation assay using phyllodes took far less time and effort to establish than the pot trials and needed a maximum of 2-3 weeks for completion, with good discrimination being apparent 5 days after inoculation among clones of $A$. mangium, A. crassicarpa and the Acacia hybrid. The trend of disease incidence (lesions and necroses) 5 days after inoculation on phyllodes was very similar to that obtained after 3 weeks using potted plants. This agrees with previous research (Magalhães et al., 2016) which showed a significant correlation between lesion width on cacao branch and leaf assays after inoculating with $C$. cacaofunesta. Newhouse et al. (2014) also found a similar result, where experimental leaf assays for lesions and necroses correlated well with stem assays for two species of chestnut after inoculating with Cryphonectria parasitica. Adoption of a phyllode inoculation assay was rapid (Chi et al., 2019; Brawner et al., 2020) following a presentation of preliminary results of this study (Nasution et al., 2016) and the heritability of the phyllode assay was almost as high as for the potted plants (Brawner et al., 2020), though those assays were assessed differently from the study described here. The strong correlation between damage indices based on internal stem lesion or phyllode damage indicate that the phyllode protocol may be a useful substitute for inoculation of potted plants.

The short duration of the screening process using phyllodes, with discrimination observed 5 days after inoculation, suggests that the phyllode assay will be particularly useful when screening a large number of Acacia clones in a breeding program. Furthermore, preliminary experiments have also indicated that there can be a delay of up to $24 \mathrm{~h}$ after sampling before the phyllodes need to be inoculated. We recorded no difference in results between phyllodes inoculated immediately after 
Fig. 11 Experiment 3 -

Phyllodes inoculated with C.manginecans code $\mathrm{C} 013$.

Values shown are discolouration index DI (\%) means (+s.e.)

averaged over 5 replicates 5 days after inoculation, using phyllodes randomly selected from 19

A. mangium clones: A Replicate

1; B Replicate 2. Clones

highlighted in grey were the three most tolerant to infection when the stems of potted plants were inoculated in this trial (see Fig. 9)
A

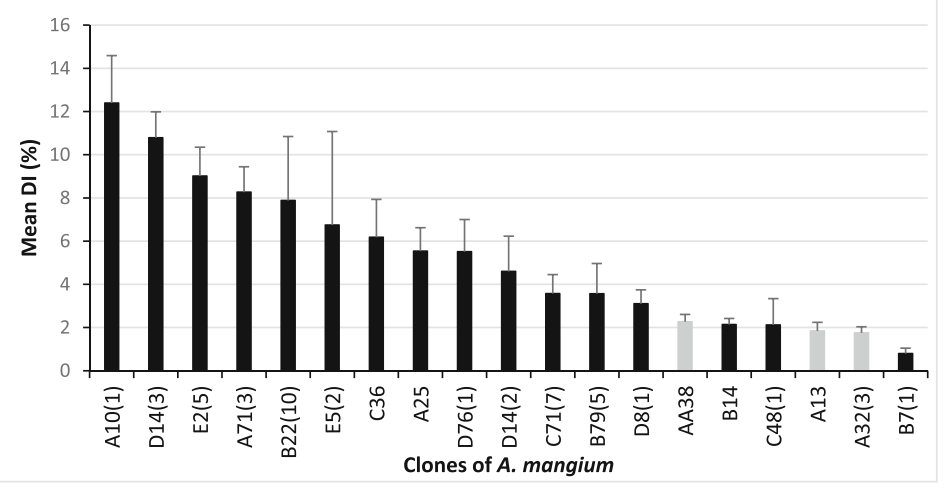

B

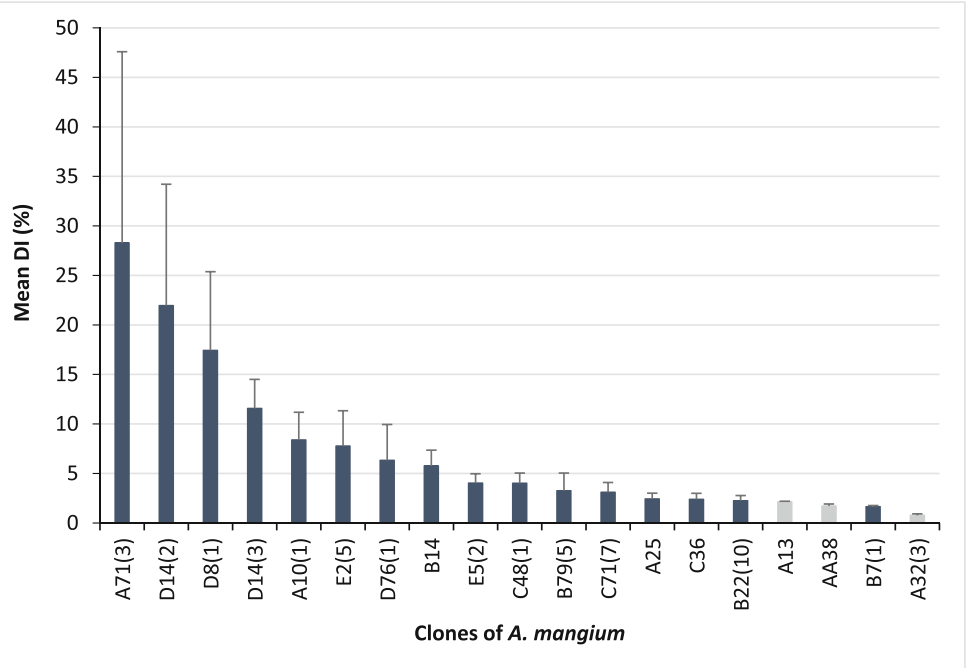

collection and those inoculated the following day after overnight storage at $4{ }^{\circ} \mathrm{C}$. A further benefit of inoculating phyllodes in the laboratory reduces the possibility of fungal inoculum spreading to the environment.

C. manginecans isolates which were used in this study showed variation in aggressiveness. Although these fungi were isolated from the same tree species (A. mangium), they were obtained from different areas, which may lead to variability in their pathogenicity. Previous studies of ceratocystis disease aggressiveness have indicated that pathogenic variability may be due to genetic variation in the isolates which correlate with geographic area of origin and host species (Baker et al., 2003; Harrington et al., 2011), though it may also be the linked to transposable effectors (Fourie et al., 2020). It is important to confirm the aggressiveness of isolates used in screening, because pathogen variability is considered a crucial point for successful resistance breeding. Variable pathogen populations evolve when there is selection for mutants, recombinants, or immigrants, and this may give rise to higher frequencies of pathogen genotypes causing severe disease on common plant cultivars (McDonald \& Linde, 2002).

The inoculum form, mycelium vs. conidia, only produced a difference in aggressiveness in the early stages of infection, with higher discolouration indices obtained using mycelium. At subsequent assessment dates, the DI showed no significant difference between mycelial plug and spore suspension. The difference of lesion length in early infection appears to be due to an immediate start of the infection process by mycelium while spores in suspension need to germinate before infecting the plant tissues. However, isolate pathogenicity and inoculum concentration are more likely to be the important factors in quantifying the plant host response. The size of the mycelium plug and concentration of the spore 
suspensions used in this study were shown to be adequate for producing stem lesions. This agrees with a study of $C$. cacaofunesta inoculation which showed that between $10^{4}$ and $10^{5}$ spores $/ \mathrm{mL}$ was an appropriate concentration for disease incidence (Sanches et al., 2008). The results of the present study indicate that either inoculum form can be used in pathogenicity tests with $C$. manginecans.

The A. crassicarpa clones used in this study were demonstrably less susceptible to $C$. manginecans infection than A. mangium, with much smaller lesions; in addition, some $A$. crassicarpa inoculated stems had no lesions. These results are similar to those of Tarigan et al. (2013), where A. crassicarpa and A. auriculiformis were more tolerant compared with A. mangium. Thus, both species can be considered as potential sources for identifying and determining the basis for resistance/tolerance to ceratocystis wilt and canker disease, and to inform future breeding efforts.

In summary, results from potted plant and phyllode assays lead to similar conclusions regarding the tolerance of Acacia clones to ceratocystis wilt and canker disease. In contrast, the stem segment procedure delivered inconsistent results and the protocol needs improvement. Compared with the potted plant and stem segment assays, the phyllode assay is much more efficient in cost and effort, allowing screening of a greater number of Acacia clones, and is easier to perform under laboratory conditions. Therefore, the phyllode inoculation protocol, with the phyllodes of Acacia being the counterpart of the leaves in other flowering plants, appears to have high potential to be used as a rapid, preliminary screening assay for genetic attributes that contribute to tolerance of ceratocystis wilt and canker disease in Acacia clones.

Supplementary Information The online version contains supplementary material available at https://doi.org/10.1007/s10658022-02479-w.

Acknowledgements This work was supported by the Australian Centre for International Agricultural Research, project.

FST/2014/068. Aswardi Nasution was the recipient of a John Allwright Fellowship.

The data that support the findings of this study are available from the corresponding author upon.

request.

Availability of data and material (data transparency) The data that support the findings of this study are available from the corresponding author upon request.
Code availability (software application or custom code) Not applicable.

Authors' contributions All authors have read and approved the final version of this publication.

Funding Open Access funding enabled and organized by CAUL and its Member Institutions. This work was supported by the Australian Centre for International Agricultural Research (ACIAR), project FST/2014/068. Aswardi Nasution was the recipient of a John Allwright Fellowship awarded by ACIAR.

\section{Declarations}

Conflict of interest The authors declare that they have no conflict of interests.

Open Access This article is licensed under a Creative Commons Attribution 4.0 International License, which permits use, sharing, adaptation, distribution and reproduction in any medium or format, as long as you give appropriate credit to the original author(s) and the source, provide a link to the Creative Commons licence, and indicate if changes were made. The images or other third party material in this article are included in the article's Creative Commons licence, unless indicated otherwise in a credit line to the material. If material is not included in the article's Creative Commons licence and your intended use is not permitted by statutory regulation or exceeds the permitted use, you will need to obtain permission directly from the copyright holder. To view a copy of this licence, visit http://creativecommons.org/licenses/by/4.0/.

\section{References}

Alonso, C., Ramos-Cruz, D., \& Becker, C. (2018). The role of plant epigenetics in biotic interactions. New Phytologist, 221, 731-737.

Asia-Pacific Forestry Commission (2010). Asia-Pacific forests and forestry to 2020: report of the second Asia-Pacific forestry sector outlook study. Asia-Pacific Forestry Commission, RAP publication 2010/06, ISBN 978-92-5106566-2, Food and Agriculture Organization of the United Nations, .

Baker, C. J., Harrington, T. C., Krauss, U., \& Alfenas, A. C. (2003). Genetic variability and host specialization in the Latin American clade of Ceratocystis fimbriata. Phytopathology, 93, 1274-1284.

Beier, G. L., \& Blanchette, R. A. (2020). Xylem characteristics in Ulmus americana cultivars and their potential use as a preliminary screening method for Dutch elm disease resistance. Forest Pathology, 50, e12638.

Brawner, J., Japarudin, Y., Lapammu, M., Rauf, R., Boden, D., \& Wingfield, M. J. (2015). Evaluating the inheritance of Ceratocystis acaciivora symptom expression in a diverse 
Acacia mangium breeding population. Southern Forests, 77, 83-90.

Brawner, J., Chi, N. M., Chi, N., Glen, M., Mohammed, C., Thu, P. Q., \& Kien, N. D. (2020). Tolerance of Acacia populations following inoculation with the Ceratocystis canker and wilt pathogen in Vietnam. Tree Genetics and Genomes, 16, 77.

Brawner, J., Sunarti, S., Nirsatmanto, A., Indrayadi, H., Tarigan, M., Yuliarto, M., Rahayu, S., Hardiyanto, E., Glen, M., Rimbawanto, A., \& Mohammed, C. (submitted). Screening clonally replicated Acacia mangium breeding populations for tolerance to to Ceratocystis canker and wilt disease.

Chi, N. M., Thu, P. Q., \& Mohammed, C. (2019). Screening disease resistance of Acacia auriculiformis clones against Ceratocystis manginecans by artificial and natural inoculation methods. Australasian Plant Pathology, 48, 617-624.

Devkota, P., \& Hammerschmidt, R. (2019). A rapid and holistic approach to screen susceptibility of Prunus species to Armillaria root rot. Forest Pathology, 49, e12547.

Fourie, A., Wingfield, M. J., Wingfield, B. D., \& Barnes, I. (2015). Molecular markers delimit cryptic species in Ceratocystis sensu stricto. Mycological Progress, 14, 1020.

Fourie, A., de Jonge, R., van der Nest, M. A., Duong, T. A., Wingfield, M. J., Wingfield, B. D., \& Barnes, I. (2020). Genome comparisons suggest an association between Ceratocystis host adaptations and effector clusters in unique transposable element families. Fungal Genetics and Biology, 143, 103433.

Francis, A., Beadle, C., Puspitasari, D., Irianto, R., Agustini, L., Rimbawanto, A., Gafur, A., Hardiyanto, E., Junarto, Hidyati, N., Tjahjono, B., Mardai, U., Glen, M., \& Mohammed, C. (2014). Disease progression in plantations of Acacia mangium affected by red root rot (Ganoderma philippii). Forest Pathology, 44, 447-459.

Hardie, M., Akhmad, N., Mohammed, C., Mendham, D., Corkrey, R., Gafur, A., \& Siregar, S. (2018). Role of site in the mortality and production of Acacia mangium plantations in Indonesia. Southern Forests, 80, 37-50.

Harrington, T.C. (2007) The genus Ceratocystis. Where does the oak wilt fungus fit? In: Billings RF, Appel DN, eds. Proceedings of the 2nd National Oak Wilt Symposium, Austin, Texas, United States, June 2007, vol. 4, 17pp.

Harrington, T. C. (2013). Ceratocystis diseases. In P. Gonthier \& G. Nicolotti (Eds.), Infectious forest diseases (pp. 230-255). CABI.

Harrington, T. C., Thorpe, D. J., \& Alfenas, A. C. (2011). Genetic variation and variation in aggressiveness to native and exotic hosts among Brazilian populations of Ceratocystis fimbriata. Phytopathology, 101, 555-566.

Harwood, C. E., \& Nambiar, E. K. S. (2014a). Productivity of acacia and eucalypt plantations in Southeast Asia. 2. Trends and variations. International Forestry Review, 16, 249-260.

Harwood, C.E., \& Nambiar, E.K.S. (2014b). Sustainable plantation forestry in South-East Asia. Australian Centre for International Agricultural Research technical reports no. 84. Canberra, ACT Australia 100pp.

Heath, R. N., Wingfield, M. J., Van Wyk, M., \& Roux, J. (2009). Insect associates of Ceratocystis albifundus and patterns of association in a native savanna ecosystem in South Africa. Environmental Entomology, 38, 356-364.

Jactel, H., Desprez-Loustau, M. L., Battisti, A., Brockerhoff, E., Santini, A., Stenlid, J., Björkman, C., Branco, M., Dehnen-
Schmutz, K., Douma, J. C., Drakulic, J., Drizou, F., Eschen, R., Franco, J. C., Gossner, M. M., Green, S., Kenis, M., Klapwijk, M. J., Liebhold, A. M., et al. (2020). Pathologists and entomologists must join forces against forest pest and pathogen invasions. NeoBiota, 58, 107-127.

Kile, G. A. (1993). Plant diseases caused by species of Ceratocystis sensu stricto and Chalara. In M. J. Wingfield, K. A. Seifert, \& J. F. Webber (Eds.), Ceratocystis and ophiostoma: taxonomy, ecology and pathogenicity (pp. 173-183). Conference proceedings, American Phytopathological Society.

Luiz, B., Stacy, E. A., \& Keith, L. M. (2020). Screening of Metrosideros polymorpha ('ohi'a) varieties for resistance to Ceratocystis lukuohia. Forest Pathology, 50, e12656.

Magalhães, D. M. A., Luz, E. D. M. N., Lopes, U. V., Niella, A. R. R., \& Damaceno, V. O. (2016). Leaf disc method for screening Ceratocystis wilt resistance in cacao. Tropical Plant Pathology, 41, 155-161.

McDonald, B. A., \& Linde, C. (2002). Pathogen population genetics, evolutionary potential, and durable resistance. Annual Review of Phytopathology, 40, 349-379.

Mohammed, C. L., Rimbawanto, A., \& Page, D. E. (2014). Management of basidiomycete root- and stem-rot diseases in oil palm, rubber and tropical hardwood plantation crops. Forest Pathology, 44, 428-446.

Nambiar, E., \& Harwood, C. (2014). Productivity of acacia and eucalypt plantations in Southeast Asia. 1. Bio-physical determinants of production: Opportunities and challenges. International Forestry Review, 16, 225-248.

Nasution, A, Glen, M., Gafur, A., Evans. K., \& Mohammed, C.L. (2016) Developing a rapid screening protocol for resistance of Acacia mangium against Ceratocystis wilt and canker disease. Workshop proceedings: ceratocystis in tropical hardwood plantations; Feb 15-16, Yogyakarta.

Newhouse, A. E., Spitzer, J. E., Maynard, C. A., \& Powell, W. A. (2014). Chestnut leaf inoculation assay as a rapid predictor of blight susceptibility. Plant Disease, 98, 4-9.

Oliveira, L. S. S., Harrington, T. C., Ferreira, M. A., Damacena, M. B., Al-Sadi, A. M., Al-Mahmooli, I. H. S., \& Alfenas, A. C. (2015). Species or genotypes? Reassessment of four recently described species of the Ceratocystis wilt pathogen, Ceratocystis fimbriata, on Mangifera indica. Phytopathology, 105, 1229-1244.

Pais, A. L., Li, X., \& Xiang, Q.-Y. (2018). Discovering variation of secondary metabolite diversity and its relationship with disease resistance in Cornus florida L. Ecology and Evolution, 8, 5619-5636.

Roux, J., \& Wingfield, M. J. (2009). Ceratocystis species: Emerging pathogens of non-native plantation Eucalyptus and Acacia species. Southern Forests, 71, 115-120.

Sanches, C. L. G., Pinto, L. R. M., Pomella, A. M. V., Silva, S. D. V. M., \& Loguercio, L. L. (2008). Assessment of resistance to Ceratocystis cacaofunesta in cacao genotypes. European Journal of Plant Pathology, 122, 517-528.

Tarigan, M., Roux, J., Van Wyk, M., Tjahjono, B., \& Wingfield, M. J. (2011a). A new wilt and die-back disease of Acacia mangium associated with Ceratocystis manginecans and C. acaciivora sp. nov. in Indonesia. South African Journal of Botany, 77, 292-304.

Tarigan, M., Wingfield, M. J., Van Wyk, M., Tjahjono, B., \& Roux, J. (2011b). Pruning quality affects infection of Acacia 
mangium and A. crassicarpa by Ceratocystis acaciivora and Lasiodiplodia theobromae. Southern Forests, 73, 187-191.

Tarigan, M., Yuliarto, M., Gafur, A., Yong, C.W., \& Sharma, M. (2013) Other Acacia species as a source of resistance to Ceratocystis. PT. Riau Andalan Pulp and Paper, APRIL, Indonesia, <http://www.biotifor.or.id/2013/lb. file/gambar/File/WorkshopCeratocystis/AbdulGafur(RAPP)-Other-Acacia-species-as-source-of-resistanceto-Ceratocystis.pdf>.

Thu, P. Q., Qynh, D. N., \& Dell, B. (2012). Ceratocystis sp. causes crown wilt of Acacia spp. planted in some ecological zones of Vietnam. Journal of Plant Protection, 5, 24-30.

Trang, T. T., Eyles, A., Davies, N. W., Glen, M., Ratkowsky, D., \& Mohammed, C. L. (2017). Screening for host responses in Acacia to a canker and wilt pathogen, Ceratocystis manginecans. Forest Pathology, 48, e12390.

Van der Westhuizen, I. P., Wingfield, M. J., Swart, W. J., \& Kemp, G. H. J. (1992). Comparison of the susceptibility of Eucalyptus clones to Cryphonectria cubensis under field and greenhouse conditions. Phytophylactica, 24, 107.
Van Wyk, M., Heath, R. N., Tarigan, M., Vermeulen, M., \& Wingfield, M. J. (2010). Comparison of procedures to evaluate the pathogenicity of Ceratocystis fimbriata sensu lato isolates from Eucalyptus in South Africa. Southern Forests, $72,56-61$.

Wingfield, M. J., Roux, J., Coutinho, T., Govender, P., \& Wingfield, B. (2001). Plantation disease and pest management in the next century. The South African Forestry Journal, 190, 67-71.

Woodcock, P., Marzano, M., \& Quine, C. P. (2019). Key lessons from resistant tree breeding programmes in the northern hemisphere. Annals of Forest Science, 76, 51.

Wright, H. (2014) Raw materials: Global pulp market trends. Paper industry world. http://www.paperindustryworld. com/raw-materials-global-pulp-market-trends/. Viewed 19 August 2019.

Zalasky, H. (1965). Process of Ceratocystis fimbriata infection in aspen. Canadian Journal of Botany, 43, 1157-1162. 